\title{
Placental site trophoblastic tumor unprecedented by conception: a very rare presentation
}

\author{
Sanjay Badesara ${ }^{1}$, Kiran Jakhar ${ }^{2 *}$
}

${ }^{1}$ Department of Surgical Oncology, Pt. BD Sharma PGIMS, Rohtak, Haryana, India
${ }^{2}$ Department of Psychiatry, Government Institute of Medical Sciences, Greater Noida, Uttar Pradesh, India

Received: 16 January 2021

Accepted: 02 February 2021

\author{
*Correspondence: \\ Dr. Kiran Jakhar, \\ E-mail: kjakhar48@gmail.com
}

Copyright: (c) the author(s), publisher and licensee Medip Academy. This is an open-access article distributed under the terms of the Creative Commons Attribution Non-Commercial License, which permits unrestricted non-commercial use, distribution, and reproduction in any medium, provided the original work is properly cited.

\section{ABSTRACT}

Placental site trophoblastic tumour is the rare variant of gestational trophoblastic neoplasia with incidence rate of approximately $1 / 100,000$ of all pregnancies. Histologically it is characterized by intermediate trophoblastic cells with few syntical elements. The index report depict a 20 years old unmarried female with no history of conception presenting with abnormal uterine bleeding and mildly elevated serum $\beta$-HCG level. Multi-modality treatment was given and she had fair outcome.

Keywords: Placental site trophoblastic tumor, Gestational trophoblastic tumor, Pregnancy

\section{INTRODUCTION}

Gestational trophoblastic disease includes complete or partial hydatidiform mole, invasive mole, choriocarcinoma, placental site trophoblastic tumors (PSTT) and epithelioid trophoblastic tumor (ETT). ${ }^{1,2}$ All these inter related tumors have varying potential for local invasion as well as metastasis. ${ }^{1}$ PSTT comprises of nearly $1-2 \%$ of all GTN and is approximately $1 / 100,000$ of all pregnancies. Till date, over three hundred cases of PSTT have been reported which emphasizes the rarity of the tumour. $^{3}$ Histologically PSTT consist of intermediate trophoblastic and few syntical elements. In majority of cases, it tends to remain localized to uterus before metastasis and is characterized by low beta-HCG. ${ }^{4}$ No universal guidelines for management of PSTT exist but multi- modality therapy with surgery, chemotherapy preferably with etoposide, methotrexate, dactinomycin, and cisplatin (EMA/EP) has shown improvement in survival.

The current case report shows the atypicality of presentation in terms that it is unprecedented by conception and response to treatment of placental site trophoblastic tumor.

\section{CASE REPORT}

Ms. X, 20 years old unmarried female presented with abnormal uterine bleeding for two months. The bleeding was associated with passage of clots, easy fatigability, loss of appetite and weight loss of $4-5 \mathrm{~kg}$ in last two months. No history of sexual contact was present. Her ultrasonogram showed uterine mass. Beta-HCG was 1809 $\mathrm{mIU} / \mathrm{ml}$.

On examination, thin built female with body mass index (BMI) of $15.4 \mathrm{~kg} / \mathrm{m}^{2}$ and puffiness all over face was seen. No mass per abdomen or lymphadenopathy was felt. CT scan abdomen and thorax showed uterus with heterogenous lesion of size $6.7 \times 8.2 \times 5.6 \mathrm{~cm}$ with multiple mesenteric lymph nodes. Pelvic magnetic resonance imaging showed bulky uterus with myometrial lesion and positive pelvic lymph nodes. Repeat beta-HCG was 2778 $\mathrm{mIU} / \mathrm{ml}, \mathrm{CA}-125$ was $44.26 \mathrm{U} / \mathrm{ml}$, CEA was $3.4 \mathrm{ug} / \mathrm{l}$. She had severe anemia and received blood transfusions. 
Histo-pathology showed intermediate trophoblastic cells and immunohistochemistry showed strongly positivity for $\mathrm{CK}$ and human placental lactogen (hPL), positive for ki-67, negative for HCG, placental alkaline phosphatase (PLAP). Based on the above findings, a diagnosis of gestational trophoblastic Neoplasia-placental site trophoblastic tumor variant was made.

Uterine lesion was resected and she received two cycles of EMA-EP. After multi-modality treatment, patient had fair outcome. She is now asymptomatic after two years of follow up.
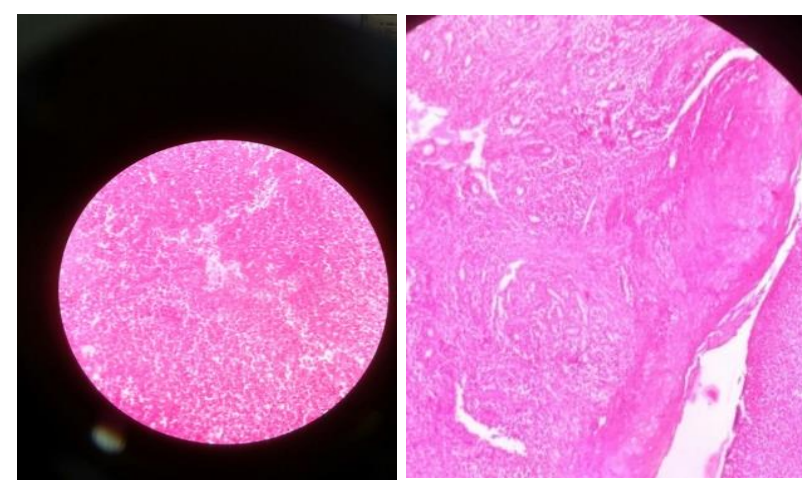

Figure 1: H \& E stained microscopic view of 10X and 40X magnification respectively showing intermediate trophoblastic cells of placental site trophoblastic tumour.

\section{DISCUSSION}

PSTT, being a rare variety of GTN, is usually preceded by pregnancy which may include a term labor or after an abortion, molar pregnancy, or ectopic pregnancy. ${ }^{5}$ However, there are rare case reports of PSTT occurring in ovary of young child and in men. ${ }^{6,7}$ The clinical manifestation comprises of amenorrhea or irregular vaginal bleeding but can also present with symptoms of metastasis. Unlike other varieties of GTN, PSTT usually presents with slightly elevated level of serum $\beta$-hCG. ${ }^{8}$ There is no appreciable relationship of serum $\beta$-hCG with malignant behavior of the tumour. ${ }^{4}$ So, it cannot accurately reflect the tumor load and has less prognostic significance. A study by Khanlian et al in 2006 found that hyperglycosylated hCG testing was more sensitive at detecting recurrent or persistent disease. ${ }^{9}$

The "gold standard" for diagnosis of PSTT is immunohistochemistry (IHC). ${ }^{10}$ On IHC, tumor cells show high level of Ki-67 expression and Inhibin. Since the tumor does not consist of syncytiotrophoblast cells, so hPL, hCG, and PLAP are rarely elevated or even absent.

Usually, total abdominal hysterectomy is the recommended surgery in women in whom preservation of fertility is not required and disease is localized to uterus. Uterine curettage alone is not sufficient in PSTT with myometrial invasion. These tumors are relatively chemo- resistant, so combination chemotherapy is advisable. ${ }^{11}$ Oophorectomy has no prognostic significance in the treatment of disease as ovarian metastasis in PSTT is not common, thus routine oophorectomy is not recommended. ${ }^{12,13}$ Commonly used chemotherapy regime is EMA/CO or EMA/EP, with $38 \%$ patients had complete response rate and overall response rate is $71 \% .^{14}$

\section{CONCLUSION}

PSTT is a rare subtype of GTN. When PSTT was diagnosed, it has preceding history of molar pregnancy, abortion or term delivery. But in the present case, no such history could be elicited which is a point of focus. Diagnosis of PSTT requires clinical examination, radiological examination, serum $\beta$-hCG and pathological examination with IHC markers.

\section{Funding: No funding sources \\ Conflict of interest: None declared \\ Ethical approval: Not required}

\section{REFERENCES}

1. Berkowitz RS, Goldenstein DS. Chorionic tumours. N Engl J Med. 1996;335:1740-8.

2. Palmer JE, MacDonald M, Wells M, Hancock BW, Tidy JA. Epitheloid trophoblastic tumour: A review of literature. J Reprod Med. 2008;53:465-75.

3. Scully RE, Young RH. Trophoblastic pseudotumor: A reappraisal. Am J Surg Pathol. 1981;5:75-6.

4. Feltmate CM, Genset DR, Wise L, Bernstein MR, Goldstein DP, Berkowitz RS. Placental site trophoblastic tumour: A 17-year experience at New England Trophoblastic Disease Center. Gynecol Oncol. 2001;82:415-9.

5. Küçük Z, Ergün Y, Işik H, Kaya F, Akgün YA, Çaydere M. A rare case of uterine rupture due to a placental site trophoblastic tumour in the rudimentary horn. J Obstet Gynaecol. 2015;35:97-8.

6. Arroyo MR, Podda A, Cao D, Rodriguez MM. Placental site trophoblastic tumor in the ovary of a young child with isosexual precocious puberty. Pediatr Dev Pathol. 2009;12:73-6.

7. Suurmeijer AJ, Gietema JA, Hoekstra HJ. Placental site trophoblastic tumor in a late recurrence of a nonseminomatous germ cell tumor of the testis. Am J Surg Pathol. 2004;28:830-3.

8. Zeng X, Liu X, Tian Q, Xue Y, An R. Placental site trophoblastic tumor: A case report and literature review. Intractable Rare Dis Res. 2015;4(3):147-51.

9. Khanlian SA, Cole LA. Management of gestational trophoblastic disease and other cases with low serum levels of human chorionic gonadotropin. J Reprod Med. 2006;51:812-8.

10. Huang F, Zheng W, Liang Q, Yin T. Diagnosis and treatment of placental site trophoblastic tumor. Int $\mathbf{J}$ Clin Exp Pathol. 2013;6:1448-51. 
11. Lan C, Li Y, He J, Liu J. Placental site trophoblastic tumor: Lymphatic spread and possible target markers. Gynecol Oncol. 2010;116:430-7.

12. Saso S, Haddad J, Ellis P, Lindsay I, Sebire NJ, McIndoe A et al. Placental site trophoblastic tumours and the concept of fertility preservation. BJOG. 2012;119:369-74

13. Shen X, Xiang Y, Guo L, Feng F, Wan X, Xiao Y et al. Fertility-preserving treatment in young patients with placental site trophoblastic tumors. Int $\mathbf{J}$ Gynecol Cancer. 2012;22:869-74.
14. Ajithkumar TV, Abraham EK, Rejnishkumar R, Minimole AL. Placental site trophoblastic tumor. Obstet Gynecol Survey. 2003;58:484-8.

Cite this article as: Badesara S, Jakhar K. Placental site trophoblastic tumor unprecedented by conception: a very rare presentation. Int J Reprod Contracept Obstet Gynecol 2021;10:1180-2. 